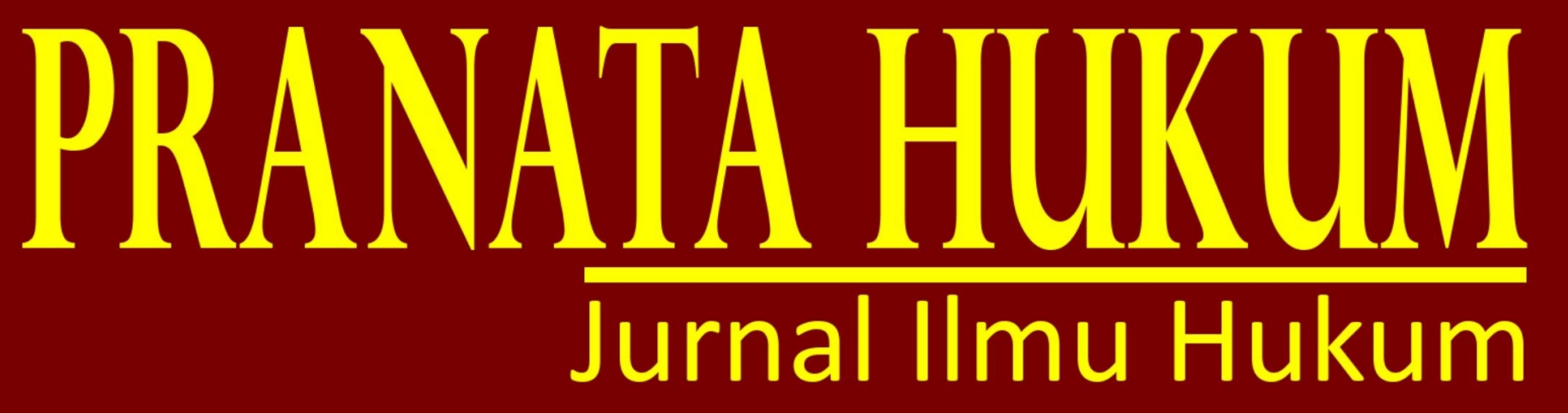

e-ISSN 2685-3213 | p-ISSN 1907-560X

EFEKTIVITAS ASEAN CONVENTION ON COUNTER TERRORISM DI DALAM MEMBERANTAS PEMBAJAKAN DI WILAYAH PERAIRAN ASIA TENGGARA

Rafi Darajati, Muhammad Syafei

PERLINDUNGAN HUKUM PENGGUNA JALAN DARI ANGKUTAN UMUM ONLINE PADA PENGGUNAAN TELEPON SAAT MENGEMUDI KENDARAAN

Rissa Afni Martinouva

ANALISIS PERTANGGUNGJAWABAN PELAKU TINDAK PIDANA MELAKUKAN PENEBANGAN POHON DALAM KAWASAN HUTAN TANPA IJIN YANG BERWENANG

Sukoco SP, Erlina B , Eddy S Wirabhumi

PERLINDUNGAN HUKUM PASIEN PADA BIDAN PRAKTIK MANDIRI DI INDONESIA PASCA DIKELUARKANNYA UNDANG-UNDANG NOMOR 4 TAHUN 2019 TENTANG KEBIDANAN Aditia Arief Firmanto

FUNGSI PENGAWASAN PERADILAN TATA USAHA NEGARA TERHADAP PERBUATAN PEMERINTAH PASCA UNDANG-UNDANG NOMOR 30 TAHUN 2014 TENTANG ADMINISTRASI PEMERINTAHAN Muhammad Rusjana

PELAKSANAAN PENGADAAN BARANG/JASA PEMERINTAH DITINJAU DARI PERPRES NOMOR 16 TAHUN 2018 TENTANG PENGADAAN BARANG/JASA PEMERINTAH DI KANTOR PERTANAHAN KOTA BANDAR LAMPUNG Aryana Wisastra, Baharudin, Indah Satria

KEWAJIBAN TANGGUNG JAWAB SOSIAL PERUSAHAAN (CORPORATE SOCIAL RESPONSIBILITY) DI INDONESIA: ANTARA LEGAL OBLIGATION ATAU MORAL OBLIGATION

Dani Amran Hakim, Dania Hellin Amrina

IMPLEMENTASI PERATURAN MENTERI AGRARIA DAN TATA RUANG/KEPALA BADAN PERTANAHAN NASIONAL NOMOR 13 TAHUN 2017 TENTANG TATA CARA BLOKIR DAN SITA PADA KANTOR PERTANAHAN KOTA BANDAR LAMPUNG

Sholin Erbin M Rajagukguk, Lintje Anna Marpaung, Herlina Ratna Sumbawa Ningrum

PEMBERIAN PATEN OBAT-OBATAN DAN PEMENUHAN HAK ASASI MANUSIA TERHADAP KESEHATAN DI INDONESIA

Chandra Muliawan

\begin{tabular}{c|c|c|c|c|}
\hline $\begin{array}{c}\text { PRANATA } \\
\text { HUKUM }\end{array}$ & $\begin{array}{c}\text { Volume } \\
14\end{array}$ & $\begin{array}{c}\text { Nomor } \\
\mathbf{2}\end{array}$ & $\begin{array}{c}\text { Halaman } \\
96-222\end{array}$ & $\begin{array}{l}\text { Bandar } \\
\text { Lampung } \\
\text { Juli 2019 }\end{array}$ \\
\hline
\end{tabular}




\section{PRANATA HUKUM}

Jurnal Ilmu Hukum

Magister Hukum

Universitas Bandar Lampung

Terbit Pertama Kali, Juli 2006

Terbit Dua Kali Setahun, Setiap Januari dan Juli

PENANGGUNG JAWAB

Rektor Universitas Bandar Lampung

KETUA PENYUNTING

Prof. Dr. Lintje Anna Marpaung, S.H., M.H

WAKIL KETUA PENYUNTING

Dr. Bambang Hartono, S.H., M.Hum

PENYUNTING PELAKSANA

Dr. Tami Rusli, S.H., M.Hum

Dr. Erlina B, S.H., M.H

Dr. Zainab Ompu Jainah, S.H., M.H

Indah Satria, S.H., M.H

Yulia Hesti, S.H., MH

\section{PENYUNTING AHLI (MITRA BESTARI)}

Prof. Dr. I Gusti Ayu Ketut Rachmi Handayani, S.H., M.M (Universitas Sebelas Maret) Prof. Dr. I Gede A.B Wiranata, S.H., M.H (Universitas Lampung)

Dr. Nurhadiantomo, S.H., M.Hum (Universitas Muhammdiyah Surakarta)

Dr. Erina Pane, S.H., M.H (UIN Lampung)

Alamat:

Kampus B Universitas Bandar Lampung

Jl. Z.A Pagar Alam No.89 Labuhan Ratu, Bandar Lampung 35142

Telp: 0721-789825 Fax: 0721-770261

Email: jurnal.mh@ubl.ac.id

Jurnal PRANATA HUKUM dimaksudkan sebagai media komunikasi ,edukasi dan informasi ilmiah bidang ilmu hukum. Sajian dan kemasan diupayakan komunikatif melalui bahasa ilmiah.

Redaksi mengundang semua elemen masyarakat ,baik civitas akademika, praktisi , lembaga masyarakat ,maupun perorangan yang berminat terhadap bidang hukum untuk berpartisipasi mengembangkan gagasan, wawasan, dan pengetahuan melalui tulisan untuk dimuat dalam jurnal ini. Melalui PRANATA HUKUM diharapkan terjadi proses pengembangan bidang hukum sebagai bagian penting dari rangkaian panjang proses memajukan masyarakat bangsa 


\title{
PERLINDUNGAN HUKUM PENGGUNA JALAN DARI ANGKUTAN UMUM ONLINE PADA PENGGUNAAN TELEPON SAAT MENGEMUDI KENDARAAN
}

\author{
Rissa Afni Martinouva ${ }^{1}$
}

\begin{abstract}
Public transportation at this time was modified by ordering technology that can be ordered online. The process of ordering this transportation tool is through an application on a smartphone or android mobile phone. Online public transportation must still comply with traffic rules. Road users other than online public transportation must also be given legal protection and together enjoy the convenience of means of traffic. The research method used is normative juridical and observation. The reason for legal protection is given to road users because as citizens who have the right to enjoy the comfort and safety of public shared road facilities. Observations made that with the attachment of communication devices on public transport online this proves the telephone is used while driving a vehicle. Communicating via telephone while driving a vehicle will cause an accident that will harm other road users. Legal protection for road users is clearly enforced through Law No. 22 of 2009 concerning LLAJ against the prohibition for motorists who carry out other activities or are affected by a situation that results in a concentration disturbance. Online motorcycle taxis should be disciplined so as not to use a telephone when driving a vehicle. The government needs to provide legal protection for road users from online public transportation in the form of a ban on the use of telephones while driving.
\end{abstract}

\section{Keywords: online, public transportation, road users.}

\section{PENDAHULUAN}

Manusia pada hakikatnya selalu memiliki keinginan untuk memenuhi kebutuhannya. Kesibukan dan aktivitas masyarakat untuk memenuhui kebutuhan sehari-hari turut menyita waktu dan mengahabiskan energi. Aktivitas atau kesibukan yang paling dirasakan menyita waktu dan menguras energi salah satu nya yaitu pengantaran ketempat tujuan yang biasanya terkendala dengan macet. Kebutuhan meliputi kebutuhan barang dan jasa. Sebuah perusahaan tidak akan memenuhi semua kebutuhan manusia, melainkan hanya sebagian saja, sedang sebagian yang lain dipenuhi oleh perusahaan lain. (Farida Hasyim, 2009: 104).

Jasa yang dapat dipakai untuk mengatasi stress ataupun kelelahan akbibat macet yaitu dengan menggunakan jasa dalam bentuk angkutan umum.

\footnotetext{
${ }^{1}$ Dosen Fakultas Hukum Universitas Malahayati Lampung, risaliadaud@gmail.com
} 
Arti jasa di antaranya adalah memberikan pelayanan yang dapat didasarkan pada prestasi dan penyedia jasa pelayanan yang menjamin mutu pelayanan yang tinggi karena ahli dan memiliki reputasi yang baik, antara lain misalnya dokter, akuntan dan advokat. (Wahyu Sasongko, 2007:70). Penelitian ini mengartikan bahwa jasa yang disediakan oleh angkutan umum online telah dikenal dan dipercaya kemampuannya memberikan pelayanan sesuai keinginan untuk memberikan pelayanan berupa jemput antar. Pelaku usaha yang membuka sarana angkutan umum online yang dimaksud pada penelitian ini tentunya sudah terdaftar dan telah lulus melalui tahap perizinan pendirian secara legalitas.

Legalitas suatu perusahaan atau badan usaha adalah merupakan unsur yang terpenting, karena legalitas adalah jatidiri yang melegalkan dan mengesahkan suatu badan usaha sehingga diakui oleh masyarakat. (Zaeni Asyhadie, 2014: 81). Angkutan umum online yang diyakini mampu mengemudi dengan baik dan telah lulus melalui seleksi kerja oleh pihak pengelolanya. Angkutan umum pada masa ini dimodifikasi cara pemesasannya dengan menggunakan teknologi aplikasi di smartphone penggunanya. Smartphone diartikan sebagai alat komunikasi pintar yang mampu digunakan untuk banyak aplikasi yang dioprasionalkan dengan cara instal atau mengaplikasikan program.

Apa itu smartphone? Pengertian Smartphone adalah telepon genggam atau telepon seluler pintar yang dilengkapi dengan fitur yang mutakhir dan berkemampuan tinggi layaknya sebuah komputer. Smartphone dapat juga diartikan sebagai sebuah telephone genggam yang bekerja dengan menggunakan perangkat lunak sistem operasi (OS) yang menyediakan hubungan standar dan mendasar bagi pengembang aplikasi.Menurut David Wood, smartphone adalah handphone cerdas yang memiliki kelebihan dibanding alat telekomunikasi lainnya. Kelebihannya terlihat dari proses pembuatannya dan proses penggunaannya. (https://www.maxmanroe.com/vid/teknologi/mobile-app/pengertian-smart phone.html diakses 16 Juli 2019)

Penumpang yang memiliki smartphone dapat dengan mudah dijemput dari tempat asalnya ke tujuan. Pemesanan yang dilakukan sering dikenal dengan angkutan umum online berupa ojek yang disediakan pelaku usaha.Pemesanan angkutan umum yang dimaksud pada penelitian ini yaitu angkutan umum dalam bentuk ojek online melalui mobil dan motor. Proses pemesanan alat angkutan ini yaitu melalui aplikasi di smartphone atau telepon selular android.

Pengemudi ojek online hanya perlu meng-aktifkan layanan ojeknya pada aplikasi yang digunakannya sebagai mitra perusahaan pengelola. Konsep yang dibuat oleh perusahaan angkutan umum ini yaitu dengan memberikan honor/gaji kepada para pengemudi ojek online sebagai pekerja yang mengantar penumpang/ pengguna jasa.

Aplikasi yang diaktifkan untuk menerima pesanan jemput antar di tempat terdekat dari pihak pelanggan / penumpang yang akan memesan. Aplikasi 
pemesanan ojek online tersebut juga memperbolehkan pembatalan pemesanan. Pembatalan pemesanan yang dilakukan apabila belum dilakukan penjemputan serta menyesuaikan dengan alasan yang disepakati. Kesepakatan yang tidak dibatalanakandilajutkan dengan melakukan perjanjian bertemu sesuai yang dituliskan tempat lokasi penjemputanpadaaplikasi.

Perjanjian akan menimbulkan hak dan kewajiban antara pihak-pihak yang harus dipenuhi berdasarkan yang diperjanjikan. Pemenuhan kewajiban bertentangan dengan wanprestasi yang tidak boleh dilakukan pihak-pihak yang melakukan perjanjian. Wanprestasi artinya tidak memenuhi kewajiban yang telah disepakati dalam perikatan. (Abdulkadir Muhammad, 2010: 241). Kewajiban angkutanumumojek online mengantar dan mendapatkan hak pembayaran dari pengguna jasa. Kewajiban pengguna jasa yaitu membayar sejumlah uang yang telah disepakati dan mendapatkan hak dijemput diantar ke lokasi yang telah disepakati pada aplikasi. Hak dan kewajiban akan menimbulkan suatu hubungan hukum antara pihak yang melakukan perjanjian.

Suatu hubungan hukum (mengenai kekayaan harta benda) antara dua orang yang memberi hak kepada yang satu untuk menuntut barang sesuatu dari yang lainnya, sedangkan orang yang lainnya ini diwajibkan memenuhi tuntutan tersebut. (Arus Akbar Silondae dan Andi Fariana, 2010: 10). Pemenuhan hak dan kewajiban antara kedua pihak akan membetuk suatu hubungan hukum serta memberikan tanggungjawab teradap perjanjian yang disepakati.

Kesepakatan yang telah dilakukan dilanjutkan dengan mengkonfirmasi tempat lokasi yang lebih tepat agar langsung dapat ditemui lokasi penjemputan. Kegiatan pemesanan tersebut dilakukan dengan cara membuka peta pada layanan peta google/ googlemaps yang dipesankan. Proses pemesanan akan menimbulkan tanya jawab ketika pencarian lokasi pelanggan yang meminta jemput. Proses komunikasi tanya jawab dilakukan dengan komunikasi melalui pesan singkat yang diketik maupun secara lisan diantara keduanya dengan telepon. Telepon yang digunakan ditempelkan di bagian kendaraan agar memudahkan saat mengemudi sambil berkomunikasi. Berkomunikasi melalui telepon pada saat mengemudi kendaraan sangatlah tidak dianjurkan, bahkan pada aturannya hal tersebut dilarang dan menghilangkan konsentrasi. Pengemudi yang sudah kehilangan konsentrasi dan terganggu dengan obrolan pada teleponnya akan sangat mungkin menimbulkan terjadi kecelakaan. Kecelakaan terjadi akan merugikan banyak pihak, terutama pengemudi tersebut, penumpang dan pengguna jalan lain.

Angkutan umum ojek online semakin populer dan berperan dalam transportasi di ibukota dan daerah saat ini dan mampu berkerjasama dengan banyak usaha-usaha sebagai kurir antar orang atau barang dari satu tempat ke tujuan yang diinginkan.

Angkutan umum online merupakan satu dari pengguna jalan yang harus tetap mematuhi aturan lalu lintas terutama pada penggunaan alat komunikasi 
sebagai alat pemesanan pengguna jasanya. Pengguna jalan selain ojek online juga harus diberikan perlindungan haknya untuk bersama-sama menikmati kenyamanan sarana lalu lintas.

Berdasarkan uraian di atas, maka masalah yang akan dibahas dalam penelitian ini adalahapa alasan sehingga perlu diberikan perlindungan hukum bagipengguna jalan dari ojek onlinepadapenggunaan telepon saat mengemudidan bagaimana bentuk perlindungan hukumnya.

\section{PEMBAHASAN}

a. Alasan Perlindungan Hukum Pengguna Jalan dari Ojek Online pada Penggunaan Telepon Saat Mengemudi Kendaraan

Pengertian transportasi dengan menggunakan aplikasi onlineberkaitan dengan perkembangan lingkungan strategis nasional dan internasional menuntut penyelenggaraan Lalu Lintas dan Angkutan Jalan yang sesuai dengan perkembangan ilmu pengetahuan dan teknologi, otonomi daerah, serta akuntabilitas penyelenggaraan negara Undang-Undang No. 22 Tahun 2009 tentang Lalu Lintas dan Angkutan Jalan (UU No. 22 Tahun 2009 tentang LLAJ). Pengguna jalan adalah orang yang menggunakan jalan untuk berlalu lintas yang diuraikan pada UU No. 22 Tahun 2009 tentang LLAJdalam ketentuan umum angka 27. Pengguna jalan bisa berupa pejalan kaki dan para pengemudi kendaraan. Pejalan kaki adalah setiap orang yang berjalan di Ruang Lalu Lintas Jalan yang diatur dalam ketentuan umum angka 26 pada UU No. 22 Tahun 2009 tentang LLAJ. Penelitian ini mengartikan pengguna jalan sebagai pihak lain yang berada disekitar ojek online beroprasional. Pengguna jalan yang dapat saja terkena dampak timbulnya kecelakaan dari pengemudi ojek online yang menggunakan telepon dan tidak konsentrasi saat mengemudi kendaraan bermotor.

Kendaraan adalah suatu sarana angkut di jalan yang terdiri atas kendaraan bermotor dan kendaraan tidak bermotor. Kendaraan bermotor adalah setiap kendaraan yang digerakkan oleh peralatan mekanik berupa mesin selain kendaraan yang berjalan di atas rel. Kendaraan tidak bermotor adalah setiap kendaraan yang digerakkan oleh tenaga manusia dan/atau hewan. Kendaraan bermotor umum adalah setiap kendaraan yang digunakan untuk angkutan barang dan/atau orang dengan dipungut bayaran.Lalu lintas dan angkutan jalan adalah satu kesatuan sistem yang terdiri atas lalu lintas, angkutan jalan, jaringan lalu lintas dan angkutan jalan, prasarana lalu lintas dan angkutan jalan, kendaraan, pengemudi, pengguna jalan, serta pengelolaannya. Lalu lintas adalah gerak kendaraan dan orang di ruang lalu lintas jalan. Angkutan adalah perpindahan orang dan/atau barang dari satu tempat ke tempat lain dengan menggunakan kendaraan di ruang lalu lintas jalan.

yang diatur dalam ketentuan umum UU No. 22 Tahun 2009 tentang LLAJ. Kendaraan angkutan umum online merupakan jenis kendaraan bermotor. 
Penumpang adalah orang yang berada di kendaraan selain pengemudi dan awak kendaraan ketentuan umum angka 25 pada UU No. 22 Tahun 2009 tentang LLAJ. Penumpang yang dimaksud pada penelitian ini adalah penumpang yang memesan angkutan umum gojek onlinedan sebagai pengguna jasa. Pemesanan dilakukan oleh penumpang sebagai pengguna jasa memalui aplikasi pada smartphone. Pengguna jasa yang meminta bantuan angkutan orang atau suatu benda yang harus diantar. Pengguna jasa yang memiliki smartphone dapat dengan mudah dijemput dari tempat asalnya ke tujuan. Pemesanan yang dilakukan sering dikenal dengan angkutan umum online.

Aplikasi yang telah diterapkan pada smarthphone jika dilakukan pemesanan maka sudah dapat diketahui jarak, lama pemesanan, harga, nama orang yang menjemput, serta perusahaan pengelolannya. Identitas pengendara sudah diketahui secara pasti karena perusahaan pengelola telah melakukan proses verifikasi terlebih dahulu sebelum melakukan kerjasama kemitraan.Beberapa hal yang bisa diketahui oleh pelanggan saat memesan ojek yaitu: identitas pengendara yang berangkat ke lokasi tujuan, info harga secara pasti dan foto pengendara. Pengemudi ojek yang selama ini harus menawarkan jasa ke pelanggan yang lewat, kini tidak perlu lagi menawarkan jasanya langsung secara lisan.

Proses pemesanan alat angkutan online memiliki beberapa keunggulan dibandingkan dengan angkutan umum biasanya karena lebih cepat, hanya fokus mengantar penumpang, harganya terjangkau dan menyusul dari tempat pengguna jasanya hingga antar ke tempat tujuan yang diinginkan misalnya yang berbentuk ojek. Pemesanan angkutan umum yang dipesan melalui online yang dimaksud pada penelitian ini yaitu yang menggunakan kendaraan mobil dan motor di antaranya : Gojek, GRAB, Uber.Angkutan umumojek online yang semakin populer telah banyak membantu dan berperan dalam transportasi di ibukota dan daerah saat ini. Angkutan umum ojek online semakin hari semakin popular di semua usia, baik orang biasa yang meminta diantar hingga pengusaha, pedagang, pekerja sebagai pengguna jasa. Ojek online mampu berkerjasama dengan banyak usaha-usaha sebagai kurir antar yang memudahkan perjalanan orang atau barang dari satu tempat ke tujuan yang diinginkan.

Aplikasi ojek online tersebut juga menampilkan sarana untuk berkomunikasi seperti saling kirim pesan dan telepon. Sarana berkomunikasi tersebut tersambung online untuk memperlancar lokasi dan permintaan lain yang diingikan oleh pelanggan dan ojek online kehendaki dan setujui bersama. Aplikasi yang diaktifkan untuk menerima pesanan jemput antar di tempat terdekat dari pihak pelanggan / penumpang yang akan memesan. Aplikasi pemesanan ojek online tersebut juga memperbolehkan pembatalan pemesanan.

Pembatalan pemesanan yang dilakukan apabila belum dilakukan penjemputan serta menyesuaikan dengan alasan yang disepakati. 
Pelanggan adalah konsumen yang harus menggunakan smartphone jika ingin melakukan pemesanan angkutan umum ojek online. Pelanggan ojek online sebelumnya telah mendaftarkan terlebih dahulu identitasnya pada aplikasi yang akan digunakan. Identitas yang diberikan berupa nama, nomor telepon pengguna yang bisa dihubungi dan alamat email. Nomor telepon dan email akan otomatis dapat diterima sebagai pelanggan jika belum pernah didaftarkan. Nomor telepon dan email yang sudah pernah didaftarkan akan terdeteksi otomatis untuk masuk sebagai nama yang pernah didaftarkan. Tempat pemesan dapat dengan mudah diangkau karena sudah otomatis mendapatkan pengemudi ojek online yang berada tidak jauh dari alamat tempat jemputan yang diantar.

Proses pemesanan ojek online akan menimbulkan tanya jawab ketika pencarian lokasi pelanggan yang meminta jemput. Proses komunikasi tanya jawab dilakukan dengan komunikasi melalui pesan singkat yang diketik maupun secara lisan diantara keduanya dengan telepon. Alat komunikasi berupa telepon dan smartphone tersebut terkadang digunakan dengan ditempelkan di bagian kendaraan yang menghadap kepengemudi ojek online. Pengamatan yang dilakukan menghasilkan jawaban bahwa dengan ditempellkannya alat komunikasi pada kendaraan ojek online maka akan memudahkan penggunaanya meskipun saat mengemudi. Keadaan tersebut membuktikan bahwa ojek onlineberkomunikasimenggunakan telepon saat mengemudi kendaraan bermotor. Berkomunikasi melalui telepon sangatlah tidak dianjurkan, bahkan pada aturannya hal tersebut dilarang. Menggunakan telepon saat mengemudikan kendaran, akan mengurangi dan menghilangkan konsentrasi.

Pengemudi yang sudah kehilangan konsentrasi dan terganggu dengan obrolan pada teleponnya akan sangat mungkin menimbulkan terjadi kecelakaan. Kecelakaan terjadi akan merugikan banyak pihak, terutama pengemudi tersebut, penumpang dan pengguna jalan lain yang berada disekitar tempat tersebut. Sarana lalu lintas juga diperuntukkan bagi seluruh pengguna jalan baik dari pejalan kaki hingga pengendara bermotor dan tidak bermotor. Penggunaan jalan harus memperhatikan rambu lalu lintas, mengatur jarak kecepatan dengan pengguna jalan lain.

Salah satu sumber utama konflik dan kekerasan di berbagai daerah adalah kondisi penegakan hukum di Indonesia yang sangat lema. Ditambah lagi dengan berbagai bentuk diskriminasi dan marginalisasi dalam pengaturan socialekonomi, politik, dan pemanfaatan sumber daya alam bahkan kehidupan budaya. Berbagai perasaan ketidakadilan dan ketidakpuasan umum pun berkecamuk dan meledak menjadi tragedi kemanusiaan yang sangat memilukan dan mengerikan. (Zainuddin Ali, 2018: 97). Konflik akan dapat dihindari dengan memberikan keadilan hukum secara tegas kepadapihak yang dirasa harus dilindungi.

Penelitian ini membahas mengenai perlindungan terhadap pengguna jalan dari angkutan umum online pada penggunaan telepon saat mengemudi kendaraan. 
Alasan perlindungan hukum diberikan kepada pengguna jalan karena sebagai warga masyarakat yang memiliki hak menikmati kenyamanan dan keamanan sarana jalanan umum bersama ojek online. Pengamatan yang dilakukan menghasilkan jawaban bahwa dengan ditempelkannya alat komunikasi pada kendaraan ojek online maka akan memudahkan penggunaanya meskipun saat mengemudi. Keadaan tersebut membuktikan bahwa ojek online berkomunikasi menggunakan telepon saat mengemudi kendaraan bermotor. Berkomunikasi melalui telepon saat mengemudi kendaraan akan sangat mungkin menyebabkan terjadinya kecelakaan yang akan merugikan banyak pihak, terutama pengemudi tersebut, penumpang dan pengguna jalan lain. Angkutan umum ojek online perlu dipertahankan keberadaanya namun dengan mematuhi aturan lalu lintas. Pemerintah perlu memberikan perlindungan hukum bagi pengguna jalan dari angkutan umum ojek online pada penggunaan telepon saat mengemudi.

\section{b. Bentuk Perlindungan Hukum Kepada Pengguna Jalan Lain dari Angkutan Umum Ojek Online pada Penggunaan Telepon Saat Mengemudi}

Angkutan umum dalam bentuk ojek online ini dibuat berdasarkan kebutuhan masyarakat yang menyesuaikan dengan gaya kehidupan di era teknologi yang semakin maju. Keberadaannya langsung diterima oleh masyarakat sebagai konsumen/pengguna jasa, meskipun pada awalnya banyak pertentangan dari ojek pangkalan disekitar tempatnya beroprasional. Pengguna jasa yang memanfaatkan saranannya mulai dari yang muda hingga yang tua, orang yang tidak bekerja maupun yang sangat padat aktivitasnya, dan para pelaku usaha dagang langsung dan pedagang online. Pengantaran barang atau orang jadi lebih mudah untuk sampai ke tempat yang diinginkan dan lebih efisien waktu serta kendaraan yang digunakan memang disediakan oleh pengemudi/pekerja dari ojek online.

Angkutan umum dalam bentuk online yang diterima masyarakat sebagai sarana yang memudahkan dan beroprasional ditengah pengguna jalan lain. Perlindungan kepada pengguna jalan dari angkutan umum online harus diberikan karena Indonesia berdasarkan Negara hukum. Menurut literature berikutmemperjelasbahwa negara Indonesia berdasarkan atas hukum (Rechsstaat) tidak berdasarkan atas kekuasan belaka (Machtsstaat) asas ini mengandung makna yang amat dalam dalam kehidupan bermasyarakat dan bernegara karena ini berarti bahwa negara (termasuk di dalamnya pemerintah, lembaga-lembaga negara, dan lembaga pemerintah serta aparatur negara) dalam melaksanakan tugasnya senantiasa harus mendasarkan diri pada hukum dan keadilan. (Ilhami Bisri, 2014: 13)

Hukum mengatur dan menguasai kehidupan berbangsa dan bernegara. Ilmu hukum mempunyai hakikat interdisipliner. 
Hakikat ini diketahui dari digunakannya berbagai disiplin ilmu pengetahuan untuk membantu menerangkan berbagai aspek yang dan berhubungan dengan kehadiran hukum di masyarakat (Satjipto Raharja, 2012: 7). Hukum dimaksudkan sebagai upaya untuk menciptakan suatu kondisi kemasyarakatan yang manusiawi dalam proses yang berlangsung secara wajar. Angkutan umum online harus dapat menyesuaikan keberadaannya di tengah masyarakat dengan memperhatikan rambu lalu lintas saat mengemudikan kendaraan. Mampu menempatkan diri secara wajar sebagai pengguna jalan agar tidak menyebabkan keelakaan atau pun keadaan buruk pada pengguna jalan lain.

Kemudahan-kemudahan dari keberadaan ojek online perlu untuk dipertahankan keberadaanya. Angkutan umum ojek online tetap ada, meskipun menurut pengamatan dari penelitian ini pengemudinya seringkali menggunakan telepon pada saat mengemudi kendaraan. Pengamatan yang dilakukan menghasilkan jawaban bahwa dengan ditempellkannya alat komunikasi pada kendaraan ojek online maka akan memudahkan penggunaanya meskipun saat mengemudi. Keadaan tersebut membuktikan bahwa ojek online menggunakan telepon saat mengemudi kendaraan bermotor. Berkomunikasi melalui telepon sangatlah tidak dianjurkan, bahkan pada aturannya hal tersebut dilarang. Menggunakan telepon saat mengemudikan kendaran akan mengurangi dan menghilangkan konsentrasi. Pengemudi yang sudah kehilangan konsentrasi dan terganggu dengan obrolan pada teleponnya akan sangat mungkin menimbulkan terjadi kecelakaan. Kecelakaan terjadi akan merugikan banyak pihak, terutama pengemudi tersebut, penumpang dan pengguna jalan lain yang berada disekitar tempat tersebut.

Angkutan umum online adalah kendaraan bermotor wajib konsentrasi dan kehati-hatian dengan memperhatikan disekitarnya ada para pejalan kaki dan pesepeda. Kehati-hatian tersebut tentu akan menjaga terjadinya kecelakaan dan tabrakan yang disebabkan kurangnya konsentrasi. Pengemudi wajib konsentrasi pada saat mengemudikan kendaraan hal ini jelas diatur pada UU No. 22 Tahun 2009 tentang LLAJ Pasal 106 bahwa setiap orang yang mengemudikan kendaraan bermotor di jalan wajib mengemudikan kendaraannya dengan wajar dan penuh konsentrasi. Setiap orang yang mengemudikan kendaraan bermotor di jalan wajib mengutamakan keselamatan pejalan kaki dan pesepeda.

Penjelasan pada UU No. 22 Tahun 2009 tentang LLAJ Pasal 106 Ayat (1) diartikan bahwa yang dimaksud dengan "penuh konsentrasi" adalah setiap orang yang mengemudikan Kendaraan Bermotor dengan penuh perhatian dan tidak terganggu perhatiannya karena sakit, lelah, mengantuk, menggunakan telepon atau menonton televisi atau video yang terpasang di Kendaraan, atau meminum minuman yang mengandung alkohol atau obat-obatan sehingga memengaruhi kemampuan dalam mengemudikan Kendaraan. 
Angkutan umum ojek online harus mampu memperhatikan dan memahami rambu-rambu lalu lintas untuk menghindari kecelakaan. UU No. 22 Tahun 2009 tentang LLAJmemberikanpengaturanbahwasetiap orang yang mengemudikan kendaraan bermotor di jalan wajib mematuhi ketentuan tentang persyaratan teknis dan laik jalan.Setiap orang yang mengemudikan kendaraan bermotor di jalan wajib mematuhi ketentuanumum: a. rambu perintah atau rambu larangan; $b$. marka jalan; c. alat pemberi isyarat lalu lintas; d. gerakan lalu lintas; e. berhenti dan parkir; f. peringatan dengan bunyi dan sinar; g. kecepatan maksimal atau minimal; dan/atau h. tata cara penggandengan dan penempelan dengan kendaraan lain. Ketentuan tersebut jika diperhatikan sangat berhubungan erat dengan sikap focus dan konsentrasi pengemudi kendaraan bermotor. Marka jalan, isyarat, peringatan, kecepatan, tata cara penggandengan dengan kendaran lain akan dapat mudah diperhatikan dan dipatuhi oleh angkutan umum ojek online jika mengemudi dengan konsentrasi. Uraian tersebut secara tegas dan wajib menunjukan bahwa pengemudi kendaraan angkutan umum wajib mematuhi ketentuan umum lalulintas.

Sadar atau tidak sadar, manusia dipengaruhi oleh peraturan-peraturan hidup bersama yang mengekang hawa nafsu dan mengatur perhubungan antarmanusia. Peraturan-peraturan hidup itu memberi ancer-ancer perbuatan mana yang boleh dijalankan dan perbuatan mana yang harus dihindari. (C.S.T. Kansil dan Christine S.T. Kansil, 2014:47). Perlindungan terhadap pengguna jalan lain dilakukan dengan aturan agar pengemudi kendaraan bermotor dapat memperhatikan rambu-rambu lalu lintas. Perlindungan juga jelas diberlakukan bahwa penngemudi kendaraan bermotor wajib mengutamakan keselamatan pejalan kaki dan pesepeda.

Pemerintah juga memberlakukan sanksi pada UU No. 22 Tahun 2009 tentang LLAJ Pasal 283 yaitu setiap orang yang mengemudikan kendaraan bermotor di jalan secara tidak wajar dan melakukan kegiatan lain atau dipengaruhi oleh suatu keadaan yang mengakibatkan gangguan konsentrasi dalam mengemudi di jalan sebagaimana dimaksud dalam pasal 106 ayat (1) dipidana dengan pidana kurungan paling lama 3 (tiga) bulan atau denda paling banyak Rp.750.000,00 (tujuh ratus lima puluh ribu rupiah).

Perlindungan terhadap pengguna jalan dilakukan dengan aturan agar pengemudi kendaraan bermotor dapat memperhatikan rambu-rambu lalu lintas hal ini ditujukan kepada pengemudi ojek online. Perlindungan juga jelas diberlakukan bahwa pengemudi kendaraan bermotor wajib mengutamakan keselamatan pejalan kaki dan pesepeda. Pemerintah memberlakukan aturan dan sanksi melalui UU No. 22 Tahun 2009 tentang LLAJ terhadap larangan bagi pengendara kendaraan yang melakukan kegiatan lain atau dipengaruhi oleh suatu keadaan yang mengakibatkan gangguan konsentrasi. Kegiatan tersebut pada penelitian ini adalah penggunaan telepon oleh ojek online pada saat mengemudi 
kendaraan. Ojek online sebaiknya dapat aturan pendisiplinan dari pusat pengelola usahanya agar tidak menggunakan telepon saat mengemudikan kendaran karena akan mengurangi dan menghilangkan konsentrasi.

\section{PENUTUP}

Alasan perlindungan hukum diberikan kepada pengguna jalan karena sebagai warga masyarakat yang memiliki hak menikmati kenyamanan dan keamanan sarana jalanan umum bersama ojek online. Pengamatan yang dilakukan menghasilkan jawaban bahwa dengan ditempelkannya alat komunikasi pada kendaraan ojek online maka akan memudahkan penggunaanya meskipun saat mengemudi. Keadaan tersebut membuktikan bahwa ojek online menggunakan telepon saat mengemudi kendaraan bermotor. Berkomunikasi melalui telepon saat mengemudi kendaraan akan sangat mungkin menyebabkan terjadinya kecelakaan yang akan merugikan banyak pihak, terutama pengemudi tersebut, penumpang dan pengguna jalan lain.

Perlindungan terhadap pengguna jalan dilakukan dengan aturan agar pengemudi kendaraan bermotor dapat memperhatikan rambu-rambu lalu lintas hal ini ditujukan kepada pengemudi ojek online. Perlindungan juga jelas diberlakukan bahwa pengemudi kendaraan bermotor wajib mengutamakan keselamatan pejalan kaki dan pesepeda. Pemerintah memberlakukan aturan dan sanksi melalui UU No. 22 Tahun 2009 tentang LLAJ terhadap larangan bagi pengendara kendaraan yang melakukan kegiatan lain atau dipengaruhi oleh suatu keadaan yang mengakibatkan gangguan konsentrasi. Kegiatan tersebut pada penelitian ini adalah penggunaan telepon oleh ojek online pada saat mengemudi kendaraan.

Angkutan umum ojek online perlu dipertahankan keberadaanya namun dengan mematuhi aturan lalu lintas. Angkutanumumonline sebaiknya dapat aturan pendisiplinan dari pusat pengelola usahanya agar tidak menggunakan telepon saat mengemudikan kendaran karena akan mengurangi dan menghilangkan konsentrasi.Pemerintah perlu memberikan perlindungan hukum bagi pengguna jalan dari angkutan umum ojek online pada penggunaan telepon saat mengemudi. 


\section{DAFTAR PUSTAKA}

\section{A. Buku}

Akbar, Arus Silondae dan Andi Fariana, Aspek Hukum Dalam Ekonomi dan Bisnis. Mitra Wacana Media, Jakarta, 2010.

Ali, Zainuddin, Filsafat Hukum. Sinar Grafika, Jakarta, 2018.

Asyhadie, Zaeni, Hukum Bisnis: Prinsip dan Pelaksanaan di Indonesia. PT RajaGrafindo Persada, Jakarta, Cetakan ke8, 2014.

Bisri, Ilhami, Sistem Hukum Indonesia: Prinsip-prinsip dan Implementasi Hukum di Indonesia. PT RajaGrafindo Persada, Cetakan ke-9, Jakarta, 2014.

Hasyim, Farida, Hukum Dagang. Sinar Grafika, Bandar Lampung, 2009.

Kansil, C.S.T. dan Christine S.T. Kansil, PT Rineka Cipta, Pengantar Ilmu Hukum Indonesia, 2014.

Muhammad, Abdulkadir, Hukum Perdata Indonesia, Citra Aditya Bakti, Bandung, 2010.

Sasongko, Wahyu 2007, Ketentuan-Ketentuan Pokok Hukum Perlindungan Konsumen, Bandar Lampung: Penerbit Universitas Lampung.

Satjipto Raharja, Ilmu Hukum, Cet.7. Citra Aditya Bakti, Bandung, 2012.

\section{B. Peraturan Perundang-undangan}

Undang-Undang Nomor 22 Tahun 2009 tentang Lalu Lintas dan Angkutan Jalan

\section{Sumber Lainnya}

David Wood, Pengertian Smartphone (https://www.maxmanroe.com /vid/teknologi/mobile-app/pengertian-smartphone.html diakses 16 Juli 2019) 


\section{PEDOMAN PENULISAN JURNAL PRANATA HUKUM}

1. Naskah bersifat orisinil, baik berupa hasil riset atau tinjauan atas suatu permasalahan hukum yang berkembang di masyarakat (artikel lepas), dimungkinkan juga tulisan lain yang dipandang memberikan kontribusi bagi pengembangan ilmu hukum.

2. Penulisan terdiri atas beberapa bab penulisan hasil penelitian terdiri dari 3BAB,yaitu ;

BAB I. PENDAHULUAN (Latar Belakang dan Rumusan Masalah) BAB II. PEMBAHASAN (Kerangka Teori dan Analisis), dan BAB III. PENUTUP (Kesimpulan dan Saran).

3. Tulisan menggunakan bahasa indonesia maupun bahasa inggris yang memenuhi kaidah bahasa yang baik dan benar,tulisan menggunakan bahasa indonesia disertai abstrak dalam bahasa inggris (200 kata) dan Kata kunci, ketentuan ini berlaku sebaliknya.

4. Setiap kutipan harus menyebutkan sumbernya, dan ditulis pada akhir kutipan dengan memberi tanda kurung (bodynote). Sumber kutipan harus memuat nama pengaran, tahun penerbitan dan halaman .Contoh : satu penulis (Bagir Manan, 1994: 20), Dua Penulis (Jimly Asshidiqqie dan M.Ali Syafa'at, 2005: 11), Tiga atau lebih penulis menggunakan ketentuan et.al (dkk). Untuk artikel dari internet dengan susunan: nama penulis, judul tulisan digaris bawah, alamat website, waktu download/unduh.

5. Naskah harus disertai dengan daftar pustaka atau referensi ,terutama yang digunakan sebagai bahan acuan langsung. Daftar pustaka dan referensi bersifat alfabetis dengan format; nama pengarang, judul buku, nama penerbit, kota terbit, dan tahun penerbitan. Contoh: Bagir Manan, Hubungan Antara Pemerintah Pusat dan Daerah Menurut UUD 1945, Pustaka Sinar Harapan, Jakarta, 1994.

6. Panjang tulisan antara 15-25 halaman, font times new roman dengan 1,15 spasi. Dalam hal hal tertentu berlaku pengecualian panjang tulisan.

7. Naskah disertai nama lengkap penulis, alamat e-mail dan lembaga tempat berafiliasi saat ini, dan hal lain yang dianggap penting. 


\section{Jurnal PRANATA HUKUM dimaksudkan sebagai}

media komunikasi, edukasi, dan informasi ilmiah bidang ilmu hukum khususnya, dan ilmu sosial pada umumnya. Sajian dan kemasan diupayakan komunikatif melalui bahasa ilmiah.

Redaksi mengundang semua elemen masyarakat baik civitas akademika, praktisi, lembaga masyarakat, maupun perorangan yang berminat terhadap bidang hukum untuk berpartisipasi mengembangkan gagasan, wawasan, dan pengetahuan melalui tulisan untuk dimuat dalam jurnal ini.

Melalui PRANATA HUKUM diharapkan terjadi proses pembangunan dan pengembangan bidang hukum sebagai bagian penting dari rangkaian panjang proses memajukan masyarakat bangsa.

Alamat Redaksi

PRANATA HUKUM

Kampus B Universitas Bandar Lampung Jl. ZA Pagar Alam No.89 Labuhan Ratu, Bandar



Telp: 0721-789825

Email: jurnal.mh@ubl.ac.id

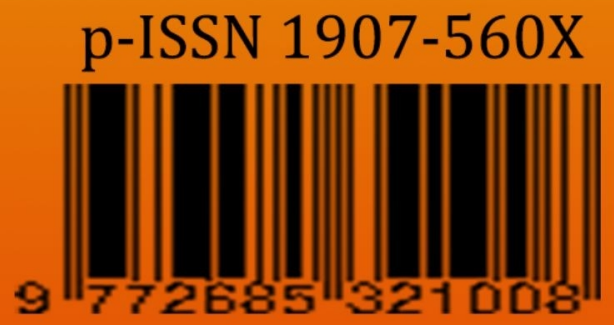

